\title{
Epstein-Barr virus and gastric carcinoma
}

\author{
K Takada
}

\begin{abstract}
The Epstein-Barr virus (EBV) is detected in the tissue of about $10 \%$ of gastric carcinoma cases throughout the world. In each case, $100 \%$ of carcinoma cells are infected with EBV. Analysis of EBV in carcinoma biopsies indicates that carcinoma is formed by the proliferation of a single EBV infected cell. These findings suggest that EBV plays an important role in the development of EBV positive gastric carcinomas. The EBV genes expressed are EBV determined nuclear antigen 1 (EBNA1), two small non-polyadenylated RNAs known as EBER1 and EBER2, and the transcripts from the BamHI-A region (BARF0); in addition, some cases also express a small amount of latent membrane protein 2A (LMP2A). Epithelial cells are refractory to $\mathrm{EBV}$ infection in vitro. This has hampered the study of the role of EBV in epithelial malignancies. The use of recombinant EBV carrying a selectable marker has enabled this difficulty to be overcome. EBV infected cell clones can be obtained from most carcinoma cell lines examined, and it was found that cell to cell contact was an efficient mode of EBV infection. Furthermore, it was possible to immortalise primary gastric epithelial cells by EBV infection. The cells expressed identical EBV genes to those typically seen in EBV positive gastric carcinoma, and showed accelerated malignant properties, including growth in soft agarose and tumorigenicity in severe combined immunodeficient (SCID) mice. These results suggest that $\mathrm{EBV}$ contributes to the maintenance of the malignant phenotype of EBV positive gastric carcinoma. (F Clin Pathol: Mol Pathol 2000;53:255-261)
\end{abstract}

Keywords: Epstein-Barr virus; gastric carcinoma; epithelial cell

The Epstein-Barr virus (EBV), originally isolated from Burkitt's lymphoma biopsies, has now been linked to various epithelioid diseases. ${ }^{1}$ Hairy leukoplakia is a lesion caused by EBV replication. The very strong association between EBV and nasopharyngeal carcinoma is already well established (see G Niedobitek, this issue). Furthermore, the development of polymerase chain reaction (PCR) and in situ hybridisation (ISH) techniques revealed the association of EBV with many other malignancies, including gastric adenocarcinoma. About $10 \%$ of gastric carcinomas throughout the world are monoclonal proliferations of EBV infected carcinoma cells. Gastric carcinoma is one of the most common carcinomas, and the worldwide occurrence of EBV positive gastric carcinoma is estimated at more than 50000 cases/year.

Unlike B cells, epithelial cells have displayed a remarkable resistance to EBV infection in vitro. This has hampered the study of the role of EBV in the development of epithelial malignancies. Therefore, we have established a system for the infection of epithelial cells in vitro, which has allowed us to study the role of $\mathrm{EBV}$ in the development of epithelial malignancies. Here, I review the literature concerning the association of EBV and gastric carcinoma, and introduce our recent findings obtained using our system for the infection of epithelial cells.

\section{Epidemiology}

Most nasopharyngeal carcinomas are undifferentiated and accompanied by intense lymphoid infiltration (termed lymphoepithelioma). Carcinomas with a similar histological profile occur at a low incidence in organs such as the salivary glands, thymus, lungs, etc, mainly in Chinese and Inuits. These carcinomas are termed lymphoepithelioma-like carcinomas or carcinomas with lymphoid stroma, and most cases are EBV positive. ${ }^{1}$ The association between EBV and gastric carcinoma was first reported in this particular type of gastric carcinoma. $^{2}$ EBV DNA was demonstrated in more than $80 \%$ of gastric carcinomas of the lymphoepithelioma type by PCR and ISH..$^{3-6}$ Subsequently, Shibata and Weiss demonstrated EBV infection in gastric adenocarcinomas of ordinary histology (fig 1). ${ }^{7}$ They reported that EBV is present in almost all carcinoma cells in EBV positive cases. Interest has increased with a report that 69 of $999(6.9 \%)$ cases of gastric carcinoma from Japan were EBV positive using ISH for the EBV encoded small RNAs (EBERs). ${ }^{8}$ Among them, the lymphoepithelioma type constituted only eight cases and the remaining cases were typical adenocarcinomas.

In contrast to Burkitt's lymphoma and nasopharyngeal carcinoma, which are endemic in equatorial Africa and Southeast Asia, respectively, ${ }^{1} \mathrm{EBV}$ positive gastric carcinoma is a non-endemic disease distributed throughout the world. However, there are some regional differences in the incidence of EBV positive gastric carcinoma as a proportion of all cases of gastric carcinoma, with the highest (16-18\%) in the USA and Germany, and the lowest (4.3\%) in China (fig 2)..$^{7-16}$ Tokunaga et al examined the incidence of EBV positive cases in gastric carcinomas of nine Japanese cities. ${ }^{17}$ The highest incidence $(10.3 \%)$ was observed in Okinawa, which has the lowest gastric carcinoma mortality rate in Japan (15.8/10 $0^{5}$ population), and the lowest incidence $(3.1 \%)$ was in Niigata, which has the highest gastric carcinoma mor-
Accepted for publication 11 July 2000 


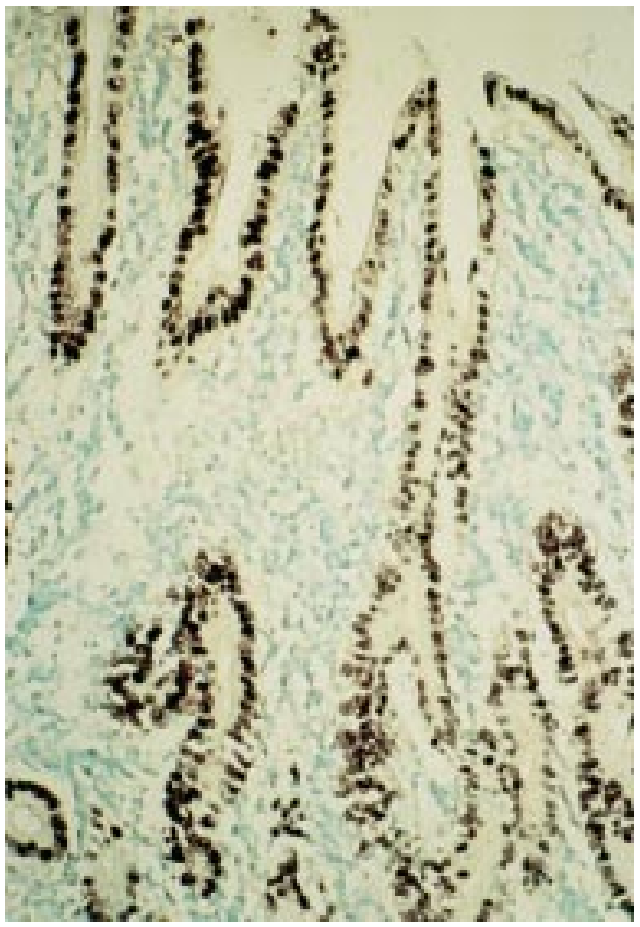

Figure 1 Detection of Epstein-Barr virus (EBV) encoded small RNA 1 (EBER1) in gastric carcinoma of the differentiated type. All carcinoma cells are positive for EBER1.

tality rate $\left(57.2 / 10^{5}\right)$. These observations suggest an inverse correlation between the incidence of gastric carcinoma and mortality from the disease. In Japan, the incidence of EBV positive gastric cancer is three times higher in men than in women, and is higher in younger men. ${ }^{8} \mathrm{EBV}$ positive cases are more frequent in the cardia $(8.1 \%)$, middle stomach $(10.6 \%)$, and gastric stump $(12.5 \%)$ than in the antrum $(3.9 \%)$. EBV involvement is seen in papillary as well as tubular adenocarcinomas. There is no difference in EBV prevalence between intestinal and diffuse types of carcinoma.

Presence and expression of EBV in carcinoma cells and non-neoplastic mucosa

EBV is not integrated into the cellular DNA of carcinoma cells, but is maintained as a plasmid. The numbers of terminal repeats (TRs) in

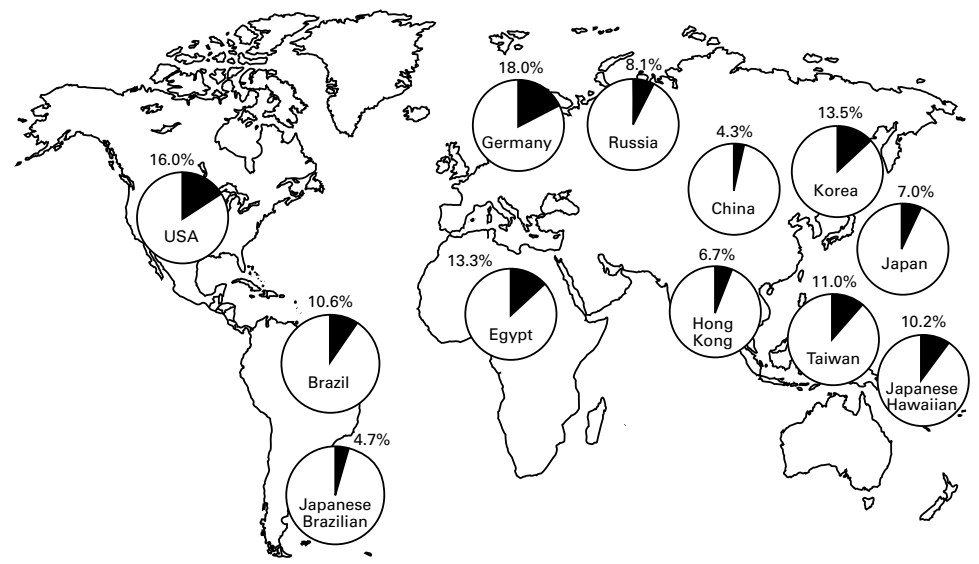

Figure 2 World distribution of Epstein-Barr virus (EBV) positive gastric carcinoma. ${ }^{16}$
EBV positive gastric carcinomas are always uniform, and therefore the tumour is derived from a single EBV infected cell (fig 3). ${ }^{711} 1819$ Taken together with the fact that $100 \%$ of carcinoma cells in EBV positive gastric carcinomas are EBV positive, this suggests that EBV plays an important role in the development of cancer. Of the six types of EBV determined nuclear antigens (EBNAs), only EBNA1 is expressed, and of the three latent membrane proteins (LMPs), LMP1 and LMP2B are not expressed, although LMP2A is expressed in some cases. In addition, the BARF0 gene from the BamHI-A region and the EBERs are always expressed. ${ }^{18}{ }^{20}$ This EBV gene expression pattern is similar to that of Burkitt's lymphoma.

In non-neoplastic gastric mucosa, scattered EBV positive cells are seen in dysplastic mucosa bordering the tumours by means of EBER ISH, but are absent in surrounding lymphocytes, other normal stromal cells, intestinal metaplasia, and normal gastric mucosa. $^{7912141921}$ These observations suggest that EBV infection occurs in the dysplastic phase and that an apparent growth advantage is conferred by the EBV infection.

Furthermore, a sensitive DNA ISH method revealed that non-neoplastic gastric epithelium, including intestinal metaplasia, is frequently infected with EBV, although EBER expression was not seen. ${ }^{22}$ A similar EBER negative EBV latency was found recently in the tissue of hepatocellular carcinoma. ${ }^{23}$ These observations highlight the danger of relying on EBER detection as the sole marker of latent EBV infection, and suggest that gastric epithelium might be a reservoir for EBV.

\section{EBV specific immunity in patients with carcinoma}

Patients with EBV positive gastric carcinoma have high IgG antibody titres against EBV capsid antigens (VCAs) and early antigens (EAs). IgA antibody against VCAs is detected in about $60 \%$ of cases, ${ }^{18}{ }^{19}$ but its diagnostic value is limited because the titres are much lower than those in nasopharyngeal carcinoma. There is evidence of high antiviral titres before the diagnosis of EBV positive gastric carcinoma. ${ }^{24}$ These findings are similar to other EBV associated malignancies and suggest that active EBV infection exists before the development of EBV positive gastric carcinoma, although EBV specific cellular immunity is not greatly reduced. ${ }^{18}$

EBV associated gastric adenocarcinomas often accompany relatively strong lymphocyte infiltration. These tumour infiltrating lymphocytes (TILs) are predominantly human leucocyte antigen (HLA) class I restricted CD8 positive cytotoxic $\mathrm{T}$ lymphocytes (CTLs), ${ }^{25}$ which kill autologous EBV immortalised cells (but not phytohaemagglutinin blast cells). ${ }^{26}$ However, they do not recognise known EBV antigenic peptides presented by HLA molecules using fibroblasts infected with vaccinia recombinant virus expressing each of the EBV latent proteins. ${ }^{26}$ These data suggest that some EBV induced proteins might be involved in the strong $\mathrm{T}$ cell response, but that this response is 


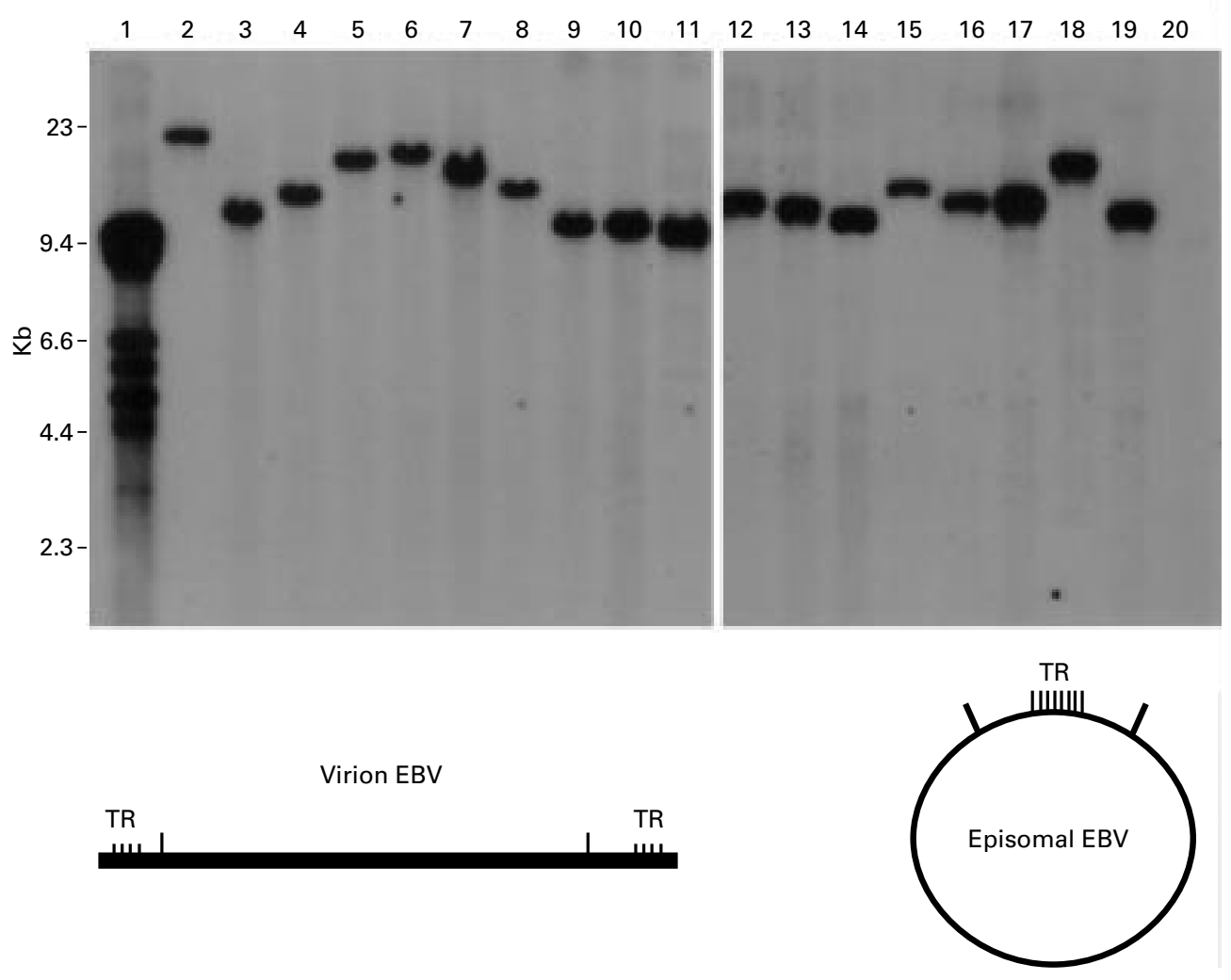

Figure 3 Epstein-Barr virus (EBV) DNA detection in EBV positive gastric carcinoma biopsies by Southern blotting. The $E B V D N A$ terminal repeat (TR) was used as a probe. A single band was detected for each gastric carcinoma tissue, indicating that the gastric carcinoma was formed by proliferation of one EBV infected cell. Lane 1, EBV producing cell line B95-8 (multiple bands because the number of viral TRs is different for each virus particle); lane 2, Burkitt's lymphoma cell line Raji (single band); lanes 3-19, EBV positive gastric carcinoma samples (single bands); lane 20, EBV negative gastric carcinoma. Kindly provided by Dr S Imai, Kochi Medical School, Kochi, fapan.

not an effective way of killing EBV infected carcinoma cells.

Factors affecting carcinoma development p53 mutation and overexpression are common in gastric carcinoma, and are detected not only in cancerous regions but also in areas of precancerous dysplasia and metaplasia. ${ }^{27}$ This suggests that p53 mutation might be an early event in gastric carcinogenesis. EBV positive gastric carcinomas tend to express much higher amounts of p53 compared with EBV negative cases. ${ }^{28}$ Leung et al have reported that nearly all EBV positive gastric carcinomas show weak to moderate p53 expression in a variable proportion of carcinoma cells, and suggest a role for $\mathrm{EBV}$ in a non-mutational mechanism of p53 overexpression. ${ }^{29}$ Such a hypothesis has also been proposed in nasopharyngeal carcinoma, in which p53 overexpression is detected in most cases yet sequence analysis has been unable to detect p53 mutation. ${ }^{3031}$

The number of apoptotic tumour cells in EBV positive gastric carcinoma is lower than that in EBV negative cases. ${ }^{32}{ }^{33}$ High bcl-2 expression in EBV positive gastric carcinoma might protect tumour cells from apoptosis. ${ }^{33}$

Helicobacter pylori infection induces chronic atrophic gastritis and subsequent intestinal metaplasia, and is linked epidemiologically with gastric carcinoma. ${ }^{34}$ Gastric carcinoma tissues are surrounded by atrophic mucosa and intestinal metaplasia in both EBV positive and
EBV negative cases. ${ }^{35}$ It is conceivable that EBV infection occurs in the atrophic epithelial cells and leads to carcinoma development. There is no significant difference in the frequency of $H$ pylori infection between EBV positive and EBV negative gastric carcinomas. ${ }^{35}$

After partial gastrectomy for benign diseases, carcinomas occur at a high frequency in the remaining stomach. ${ }^{36}$ This is referred to as gastric remnant cancer or stump cancer. The cancer risk increases with increasing length of the postoperative interval. Several explanations have been proposed for the high risk. Prolonged exposure to reflux of alkaline bile and pancreatic juices stimulates mucosal cell proliferation. ${ }^{37}$ The prevalence of EBV involvement in remnant carcinomas is significantly higher $(27 \%)$ than in non-remnant carcinomas. $^{38}$

The $30 \mathrm{bp}$ deletion in the C-terminus of the LMP1 gene has been implicated in the pathogenesis of nasopharyngeal carcinoma and Hodgkin's disease. However, this deletion might not be relevant in the pathogenesis of EBV associated gastric carcinoma because high prevalence of the deletion in gastric carcinomas reflects the prevalence of the deletion variant in the normal population. ${ }^{39}$ The situation is similar for the EBNA1 variant with a deletion in the C-terminus. ${ }^{40}$

No specific linkage to HLA subtype has been reported in patients with EBV positive gastric 
carcinoma. ${ }^{41}$ EBNA3B is a major antigenic target that elicits an HLA-A11 CTL response to EBV infection. Mutations in the HLA-11 epitopes of EBNA3B are common in EBV associated gastric carcinomas, but are not related to the patient's HLA status. ${ }^{42}$

\section{In vivo and in vitro models of $\mathrm{EBV}$ infection of epithelial cells}

In addition to nasopharyngeal carcinoma and gastric carcinoma, many examples of EBV infection of epithelial cells in vivo are known, including AIDS related hairy leukoplakia, which is a proliferative EBV lesion in the lingual epithelium, ${ }^{43}$ and EBV infection of the salivary gland epithelium. ${ }^{44}$ However, in vitro, in comparison with the infection of $\mathrm{B}$ cells, infection of epithelial cells is more difficult. EBV adheres to $B$ cells through CD21 molecules expressed on these cells, and this determines the $\mathrm{B}$ cell tropism. ${ }^{45}$ In contrast, epithelial cells are CD21 negative and this is believed to be why infection is not established, especially because they become susceptible to EBV infection when the barrier is overcome by CD21 expression via gene transfer ${ }^{46}$ or membrane implantation. ${ }^{47}$

We have shown clear evidence for direct infection of various human epithelial cells by EBV in vitro. ${ }^{48}{ }^{49}$ The infection was achieved by the use of recombinant EBV (Akata strain) carrying a selectable marker gene, ${ }^{50}{ }^{51}$ but without any other artificial operations, such as introduction of the CD21 gene. The cells used were 21 human carcinoma cell lines including those of the stomach, lung, and colon, normal human fibroblasts, and five non-human epithelial and fibroblast cell lines. Infection was accomplished by two methods: direct contact with high titre virus supernatant; and mixed culture with recombinant EBV producing

Table 1 Efficiency of Epstein-Barr virus (EBV) infection of epithelial cell lines

\begin{tabular}{|c|c|c|c|c|}
\hline \multirow[b]{2}{*}{ Cell line } & \multicolumn{2}{|l|}{ Coculuture* } & \multicolumn{2}{|l|}{ Virus supernatant } \\
\hline & $\begin{array}{l}\text { EBNA1+ cells at } \\
\text { days } 3-5(\%)^{\star *}\end{array}$ & $\begin{array}{l}\text { No. of } E B V \\
\text { convertants } / 4 \times \\
10^{5} \text { initial cells }\end{array}$ & $\begin{array}{l}\text { EBNA1+ cells at } \\
\text { days 3-5 }(\%)^{\star *}\end{array}$ & $\begin{array}{l}\text { No. of } E B V \\
\text { convertants } 4 \times \\
10^{5} \text { initial cells }\end{array}$ \\
\hline MKN1 & 2.1 & 50 & 0 & 0 \\
\hline NU-GC-3 & 15.0 & 5320 & 0 & 6 \\
\hline MKN74 & 3.3 & 444 & 0 & 4 \\
\hline HuCC-T1 & 0.5 & 28 & 0 & 0 \\
\hline HepG2 & 17.8 & 255 & 1.5 & 0 \\
\hline Нер-2 & 0.6 & 214 & 0 & 0 \\
\hline EBC-1 & 2.6 & 63 & 0 & 0 \\
\hline LK-2 & 1.4 & 0 & 0 & 0 \\
\hline PC10 & 1.8 & 4 & 0 & 0 \\
\hline RERF-LC-MS & 0.8 & 122 & 0 & 0 \\
\hline LC-1 sq & 0.1 & 0 & 0 & 0 \\
\hline DLD-1 & 4.8 & 2765 & 0.2 & 32 \\
\hline LoVo & 19.4 & 468 & 2.1 & 0 \\
\hline WiDr & 0.1 & 0 & 0 & 0 \\
\hline $\mathrm{CaR} 1$ & 0.1 & 4 & 0 & 0 \\
\hline NT-2 & 2.9 & 208 & 0.1 & 0 \\
\hline $\mathrm{T} 24$ & 0.7 & 122 & 0 & 0 \\
\hline 293 & 3.3 & 1360 & 0 & 0 \\
\hline $\mathrm{HeLa}$ & 0 & 0 & 0 & 0 \\
\hline A549 & 0 & 0 & 0 & 0 \\
\hline SMKT-R-3 & 0 & 0 & 0 & 0 \\
\hline MRC-5 & 0 & 0 & 0 & 0 \\
\hline COS-7 & 0 & 0 & 0 & \\
\hline BHK & 0 & 0 & 0 & 0 \\
\hline Rat1 & 0 & 0 & 0 & 0 \\
\hline NIH 3T3 & 0 & 0 & 0 & 0 \\
\hline CHO-K & 0 & 0 & 0 & 0 \\
\hline
\end{tabular}

$\star$ The ratio of virus donors to recipients was 10 to 1 .

${ }^{\star \star} \mathrm{EBV}$ encoded nuclear protein 1 (EBNA1)-cytokeratin double positive cells.
Akata cells. After infection, cells were cultured in G418 containing medium and EBV infected cells were selected. Continuous EBV infected cell clones were obtained from three human carcinoma lines by the virus supernatant, and from 15 human carcinoma lines by the mixed culture method (table 1). In all of the continuously infected cell clones, only EBER, EBNA1, LMP2A, and BARF0 were expressed constitutionally .

Sixbey and Yao have reported that in the pathway whereby IgA in the blood is processed into the secreted form by epithelial cells, EBV is incorporated into the epithelial cells in a bound state with IgA antibody against envelope protein. ${ }^{52}$ This phenomenon could explain the involvement of EBV infection in the development of nasopharyngeal carcinoma and possibly of gastric carcinoma, which are typically preceded and accompanied by the appearance of virus specific $\operatorname{IgA}$ in serum. Our data, however, point to another conceivable method of infection in vivo, in which cell to cell contact with virus producers is another efficient mode of EBV infection. The virus donors are most likely EBV infected B cells migrating into the epithelial stroma or intraepithelial space.

In our studies, most of the epithelial cell lines that were successfully infected with EBV were CD21 negative, and the infection was not inhibited by anti-CD21 monoclonal antibodies (OKB7). The results indicate that EBV infects epithelial cells through a receptor other than CD21. On the other hand, Fingeroth et al have reported that EBV can infect a human epithelial cell line, 293, in a CD21 dependent manner. ${ }^{53}$ These results suggest that EBV might be able to infect epithelial cells by more than one mechanism.

As in nasopharyngeal carcinoma, attempts to establish EBV positive gastric carcinoma cell lines have been unsuccessful. However, an EBV positive gastric carcinoma cell line that is transplantable in severe combined immunodeficient mice (SCID) mice (KT) has been established. ${ }^{54}$ The cell line retains the same clonal EBV genome and pattern of EBV gene expression as the original tumour biopsy. Thus, only the EBERs and Qp driven EBNA1 are expressed. This KT cell line could be an excellent in vivo model for studying the role of EBV in the development of gastric carcinoma. Two EBV positive epithelial cell lines have been established from non-cancerous portions of the stomachs of two patients with gastric carcinoma. ${ }^{55}{ }^{56}$ Both cell lines express EBNA2 and LMP1, and spontaneously produce infectious viruses. These viruses are unique in that they have the ability to transform primary B cells and induce EA in latently EBV infected Raji cells. Apart from the P3HR-1 cell line, EA inducing virus has been reported in the nasopharyngeal carcinoma-KT cell line ${ }^{57}$ and a nasopharyngeal carcinoma cell line. ${ }^{58}$ The former is a nasopharyngeal carcinoma hybrid cell line obtained by fusing primary nasopharyngeal carcinoma cells with an epithelial cell line derived from a human adenoid tissue. EA inducing virus might therefore be more prevalent in epithelial tissues. 
With regard to the virus strain dependent difference in infection efficiency suggested previously ${ }^{46}{ }^{59}$ our preliminary results indicate that the B95-8 strain of EBV is also infectious to epithelial cells. However, we have not determined the relative infection efficiencies of Akata and $\mathrm{B} 95-8$ viruses.

\section{Growth promoting effects of EBV in epithelial cells}

EBV immortalises B cells in vitro. EBNA2 and LMP1 appear to play the most important roles in the immortalisation of lymphocytes. ${ }^{60}$ However, these molecules are not expressed in EBV associated gastric carcinoma, raising doubts about the importance of the presence of EBV. We and others have analysed the Akata Burkitt's lymphoma cell line, which retains type I EBV latency in vitro, and have demonstrated that the presence of EBV is essential for the maintenance of the malignant phenotype and apoptosis resistance. ${ }^{61-64}$ Therefore, it is also possible that EBV contributes to the development and maintenance of gastric carcinomas, as described for Akata Burkitt's lymphoma cells.

We attempted to infect gastric primary culture cells with EBV. ${ }^{65}$ Twenty one primary cell cultures from healthy gastric mucosa obtained by endoscopic biopsy were infected with EBV carrying a neomycin resistance gene

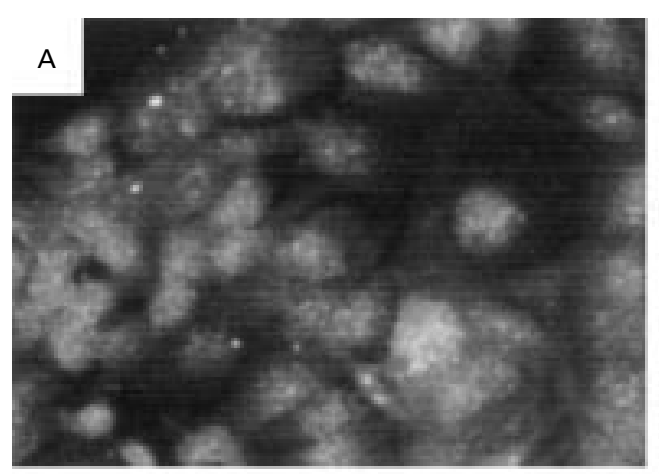

$\left(\mathrm{Neo}^{\mathrm{r}}\right)$, and infected cells were selected for using G418. As a result, EBNA expression (up to $0.2 \%$ ) was observed in three of the cultures by three days after infection; in addition, from one culture we repeatedly separated cell clones that could be maintained for at least 300 generations. These cell clones were all 100\% EBNA positive (fig 4) and expressed only the EBV genes EBNA1, EBER, BARF0, and LMP2A, similar to EBV positive gastric carcinomas. The EBV infected clones had higher proliferation rates and at least twice the cell saturation density in $10 \%$ serum compared with non-infected clones into which the $\mathrm{Neo}^{\mathrm{r}}$ gene had been introduced as a control (fig 5), and the malignant phenotype was confirmed by colony formation in soft agar.

Normal gastric mucosal primary culture cells die after subculturing for a few generations, but one of the cultured cells from which the EBV infected clones were obtained was successively subcultured to a maximum of 60 generations without EBV infection. Therefore, the cells were not completely normal, but already had a functional abnormality in the p53 protein. These results suggest that EBV alone is not sufficient for oncogenesis, but can contribute to oncogenesis together with p53 or other gene abnormalities.

Differences in proliferation as a result of EBV infection were found not only in primary culture

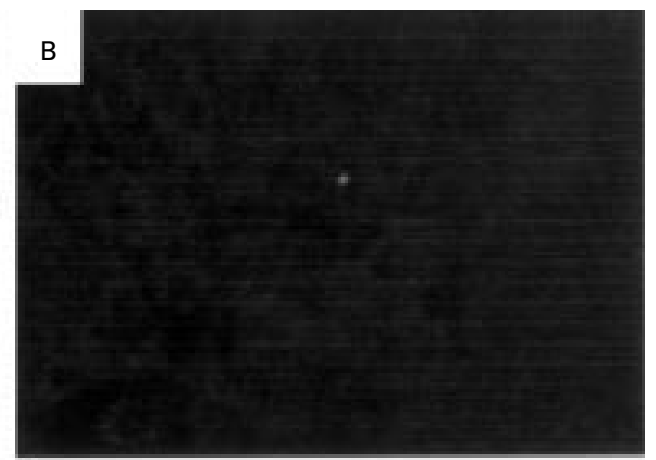

C

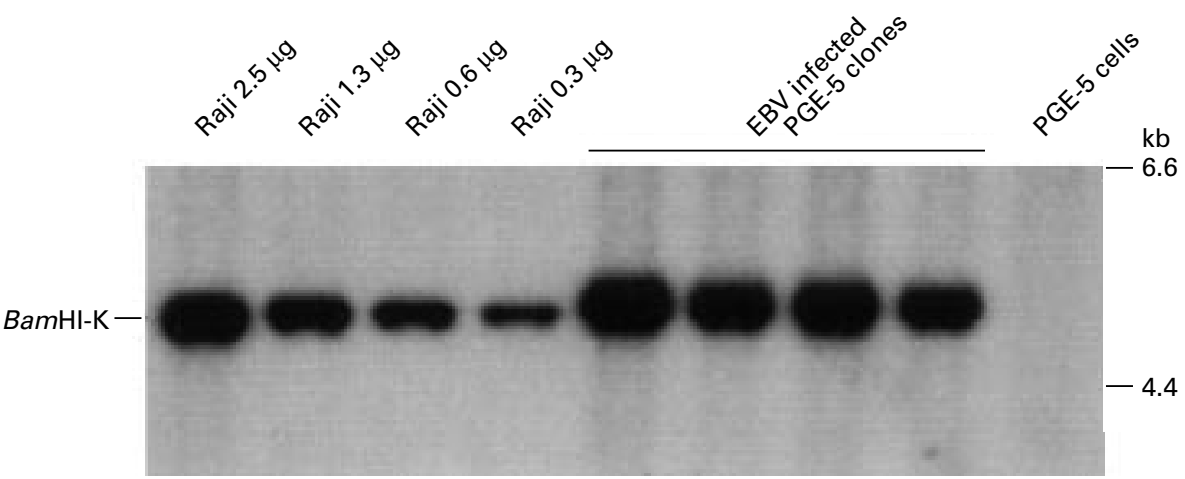

Figure 4 Detection of Epstein-Barr virus (EBV) in G418 resistant PGE-5 clones. (A) Immunofluorescent staining of $E B V$ determined nuclear antigen (EBNA) in a G418 resistant $P G E-5$ clone with $E B V$ seropositive human serum.

Original magnification, $\times 400$. (B) Immunofluorescent staining of the same clone with EBV seronegative human serum as a control. Original magnification, $\times 400$. (C) Southern blot analysis of G418 resistant PGE-5 clones. All DNA samples were digested with BamHI and the blot was probed with a BamHI-K fragment of EBV DNA. Serially diluted Raji cell $D N A$ served as positive controls. Each lane contained $5 \mu \mathrm{g}$ of DNA. All G418 resistant PGE-5 clones were estimated to carry more than 25 copies of the EBV genome/cell. Reproduced from Nishikawa et al. ${ }^{65}$ 


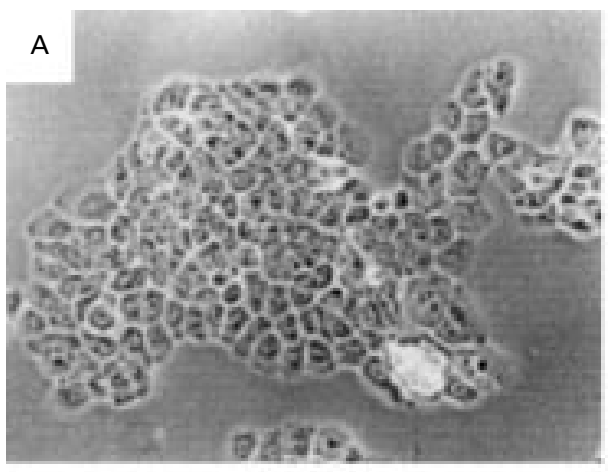

C

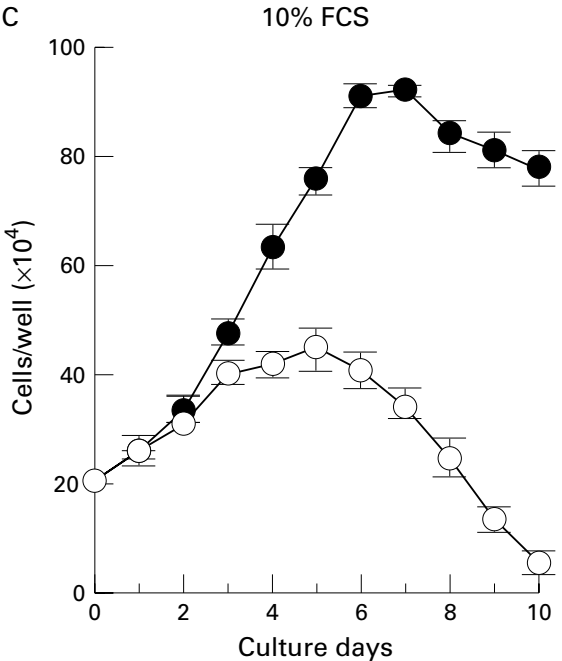

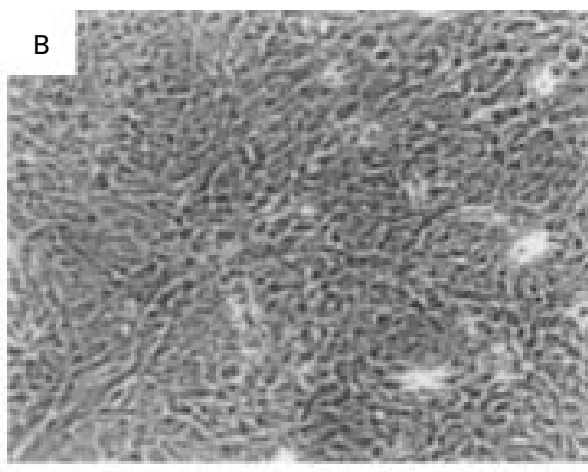

$0.1 \%$ FCS

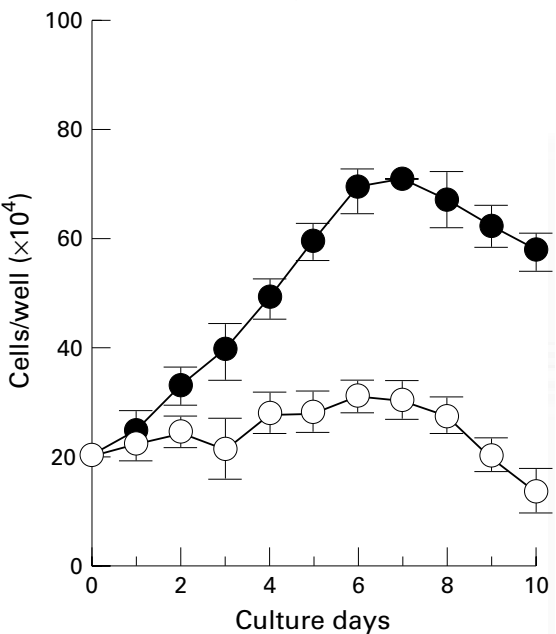

Figure 5 Growth characteristics of neomycin resistance gene (Neor) transfected and Epstein-Barr virus (EBV) infected $P G E-5$ clones. (A) Neo transfected PGE-5 clone. Original magnification, $\times 100$. (B) EBV infected PGE-5 clone. Original magnification, $\times 100$. Both clones were detached by trypsinisation, seeded into separate wells of 12 well plates under the same culture conditions, and photographed near the plateau phase (five days after passage). Differences between the two cell types are easily recognisable. (C) Growth kinetics of EBV infected (closed circle) and Neor transfected (open circle) PGE-5 cells at normal $(10 \%$; left) and low (0.1\%; right) fetal calf serum (FCS) concentrations. Each point represents the mean $\pm S E$ of the results for four clones. Reproduced from Nishikawa et al. ${ }^{6}$

cells but also in some gastric carcinoma cell lines. The gastric carcinoma cell line NUGC3 showed the greatest difference, with a shorter cell doubling time, greater cell saturation density in $10 \%$ serum, and higher proliferation in soft agar. These results, together with the results for the primary culture cells, suggest that EBV expression in EBV positive gastric carcinomas contributes to cell malignancy.

\section{Conclusions}

It is clear that EBV is associated with some cases of gastric carcinoma. Thus far, many studies have focused on the mechanisms of immortalisation of primary B cells, and these studies revealed that LMP1 and EBNA2 are important for this process. ${ }^{60}$ On the other hand, in gastric carcinoma, in which a limited number of EBV genes are expressed, very little is known, largely because of the lack of a suitable in vitro system. We have developed a system of infecting epithelial cells with EBV, which simulates in vivo EBV expression. ${ }^{48} 49$ Comparison with uninfected cells has shown that the expression of a restricted set of EBV genes, which is similar to EBV positive gastric carcinoma, accelerates cellular proliferation and provokes malignancy. ${ }^{65}$ Thus, we have shown that EBV could contribute to the devel- opment of epithelial malignancies. A topic for future research will be to determine how and by what mechanism EBV causes these changes. We have developed a method of investigating this topic and are working towards an answer.

\section{Note added in proof}

The EBV BARF1 gene has been shown previously to act as an oncogene in several cell lines. ${ }^{66}$ Zur hausen et al have recently reported that the BARF1 gene is expressed in EBV carrying gastric adenocarcinomas, ${ }^{67}$ thus suggesting that the BARF1 gene might act as the viral oncogene in EBV carrying gastric carcinomas.

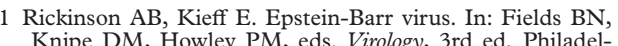
Knipe DM, Howley PM, eds. Virology,
phia: Lippincott-Raven, 1996:2397-446.

2 Burke AP, Yen TSB, Shekitka KM, et al. Lymphoepithelial carcinoma of the stomach with Epstein-Barr virus demonstrated by polymerase chain reaction. Mod Pathol 1990;3: 377-80.

3 Shibata D, Tokunaga M, Uemura Y, et al. Association of Epstein-Barr virus with undifferentiated gastric carcinomas with intense lymphoid infiltration. Am F Pathol 1991;139: 469-74.

4 Oda K, Tamaru J, Takenouchi T, et al. Association of Epstein-Barr virus with gastric carcinoma with lymphoid stroma. Am F Pathol 1993;143:1063-71.

5 Takano Y, Kato Y, Sugano H. Epstein-Barr virus-associated medullary carcinomas with lymphoid infiltration of the medullary carcinomas with lymphoid infiltration

6 Nakamura S, Ueki T, Yao T, et al. Epstein-Barr virus in gastric carcinoma with lymphoid stroma. Cancer 1994;73: tric carcin 
7 Shibata D, Weiss LM. Epstein-Barr virus-associated gastric adenocarcinoma. Am f Pathol 1992;140:769-74.

8 Tokunaga M, Land CE, Uemura Y, et al. Epstein-Barr virus in gastric carcinoma. Am ₹ Pathol 1993;143:1250-4.

9 Leoncini L, Vindigni C, Megha T, et al. Epstein-Bar virus and gastric cancer: data and unanswered questions. Int $\mathcal{F}$ Cancer 1993;53:898-901.

10 Shibata D, Hawes D, Stemmermann GN, et al. Epstein-Barr virus-associated gastric adenocarcinoma in Hawaii Japanese. Cancer Epidemiol Biomarkers Prev 1993;2:213-17.

11 Ott G, Kirchner T, Muller-Hermelink HK. Monoclonal Epstein-Barr virus genomes but lack of EBV-related protein expression in different types of gastric carcinoma. Histopathology 1994;25:323-9.

12 Yuen ST, Chung LP, Leung SY, et al. In situ detection of Epstein-Barr virus in gastric and colorectal adenocarcinomas. Am f Surg Pathol 1994;18:1158-63.

13 Nourad M, Anwar N, Magrath I, et al. Epstein-Barr virus associated gastric adenocarcinomas among Egyptians. associated gastric adenocarcinon
Cancer Mol Biol Res 1994;1:283-8.

14 Harn H, Chang J, Wang M, et al. Epstein-Barr virusassociated gastric adenocarcinoma in Taiwan. Hum Pathol 1995;26:267-71

15 Shin WS, Kang MW, Kang JH, et al. Epstein-Bar virus-associated gastric adenocarcinomas among Koreans. Am 7 Clin Pathol 1996;105:174-81.

16 Tashiro Y, Arikawa J, Itoh T, et al. Clinico-pathological findings of Epstein-Barr virus-related gastric cancer. In: Osato T, Takada K, Tokunaga M, eds. Epstein-Barr virus and human cancer. Japanese Cancer Association Gann Monograph on Cancer Research No. 45. Basel: Karger, 1998:87-97.

17 Tokunaga M, Uemura Y, Tokudome T, et al. Epstein-Barr virus related gastric cancer in Japan: a molecular pathovirus related gastric cancer in Japan: a molecular patho-

18 Imai S, Koizumi S, Sugiura M, et al. Gastric carcinoma: monoclonal epithelial malignant cells expressing EpsteinBarr virus latent infection protein. Proc Natl Acad Sci U S A 1994;91:9131-5.

19 Fukayama M, Hayashi Y, Iwasaki Y, et al. Epstein-Barr virus-associated gastric carcinoma and Epstein-Barr virus infection of the stomach. Lab Invest 1994;73:73-81.

20 Sugiura M, Imai S, Tokunaga M, et al. Transcriptional analysis of Epstein-Barr virus gene expression in EBVpositive gastric carcinoma; unique viral latency in the tumour cells. Br F Cancer 1996;74:625-31.

21 Gulley ML, Pulitzer DR, Eagan PA, et al. Epstein-Barr virus infection is an early event in gastric carcinogenesis and is independent of bcl-2 expression and p53 accumulation. Hum Pathol 1996;27:20-7.

22 Yanai $\mathrm{H}$, Takada K, Shimizu N, et al. Epstein-Barr virus infection in non-carcinomatous gastric epithelium. F Pathol 1997;183:293-8.

23 Sugawara Y, Mizugaki Y, Uchida T, et al. Detection of Epstein-Barr virus (EBV) in hepatocellular carcinoma Epstein-Barr virus (EBV) in hepatocellular carcinoma
tissue: a novel EBV latency characterized by the absence of tissue: a novel EBV latency characterized by the absence of EBV-encode

24 Levine PH, Stemmermann G, Lennette ET, et al. Elevated antibody titers to Epstein-Barr virus prior to the diagnosis of Epstein-Barr-virus-associated gastric adenocarcinoma. Int $\mathcal{f}$ Cancer 1995;60:642-4.

25 Saiki Y, Ohtani H, Naito Y, et al. Immunophenotypic characterization of Epstein-Barr virus-associated gastric carcinoma: massive infiltration by proliferating CD8+ T-lymphocytes. Lab Invest 1996;75:67-76

26 Kuzushima K, Nakamura S, Nakamura T, et al. Increased frequency of antigen-specific CD8+ cytotoxic T lymphocytes infiltrating an Epstein-Barr virus-associated gastric carcinoma. F Clin Invest 1999;104:163-71.

27 Shiao Y, Rugge M, Correa P, et al. p53 alteration in gastric precancerous lesions. Am f Pathol 1994;144:511-17.

28 Ojima H, Fukuda T, Nakajima T, et al. Infrequent overexpression of p53 protein in Epstein-Barr virusassociated gastric carcinomas. Fpn f Cancer Res 1997;88 $262-6$

29 Leung SY, Chau KY, Yuen ST, et al. p53 overexpression is different in Epstein-Barr virus-associated and Epstein-Barr virus-negative carcinoma. Histopathology 1998;33:311-17.

30 Sun Y, Hegamyer G, Cheng Y, et al. An infrequent poin mutation of the $\mathrm{p} 53$ gene in human nasopharyngeal

31 Spruck III CH, Tsai YC, Huang DP, et al. Absence of p53 gene mutations in primary nasopharyngeal carcinomas. Cancer Res 1992;52:4787-90.

32 Ohfuji S, Osaki M, Tsujitani S, et al. Low frequency of apoptosis in Epstein-Barr virus-associated gastric carciapoptosis in Epstein-Barr virus-associated gastric carci-

33 Kume T, Oshima K, Shinohara T, et al. Low rate of apoptosis and overexpression of bcl-2 in Epstein-Barr virus-associated gastric carcinoma. Histopathology 1999;34:502-9.

34 Parsonnet J, Friedman GD, Vandersteen DP, et al. Helicobactor pylori infection and the risk of gastric carcinoma. N Engl f Med 1991;325:1127-31.

35 Yanai H, Murakami T, Yoshiyama H, et al. Epstein-Barr virus-associated gastric carcinoma and atrophic gastritis. $\mathscr{F}$ Clin Gastroenterol 1999;29:39-43.

36 Caygill CPJ, Hill MJ, Kirkham JS, et al. Mortality from gastric cancer following gastric surgery for peptic ulcer. Lancet 1986;i:929-31

37 Houghton PWJ, Mortensen NJM, Williamson RCN. Effect of duodenogastric reflux on gastric mucosal proliferation of duodenogastric reflux on gastric mucosal proi
after gastric surgery. Br f Surg 1987;74:288-91.

38 Yamamoto N, Tokunaga M, Uemura Y, et al. Epstein-Barr virus and gastric remnant cancer. Cancer 1994;74:805-9.
39 Mori S, Itoh T, Tokunaga M, et al. Deletions and single-base mutations within the carboxy-terminal region of the latent membrane protein 1 oncogene in Epstein-Barr virusrelated gastric cancers of Southern Japan. 7 Med Virol 1999;57:152-8

40 Chen Y, Chang KL, Chen W, et al. Epstein-Barr virus-associated nuclear antigen-1 carboxy-terminal gene sequences in Japanese and American patients with gastric carcinoma. Lab Invest 1998;78:877-82.

41 Qiu K, Tomita Y, Hashimoto M, et al. Epstein-Barr virus in gastric carcinoma in Suzhou, China and Osaka, Japan: association with clinico-pathologic

42 Chu PG, Chang KL, Chen W-G, et al. Epstein-Barr virus (EBV) nuclear antigen (EBNA)-4 mutation in EBVassociated malignancies in three different populations. Am a Pathol 1999;155:941-7.

43 Greenspan JS, Greenspan D, Lennette ET, et al. Replication of Epstein-Barr virus within the epithelial cells of oral "hairy" leukoplakia, an AIDS-associated lesion. N Engl $\mathcal{F}$ Med 1985;313:1564-71.

44 Wen S, Shimizu N, Yoshiyama $\mathrm{H}$, et al. Association of Epstein-Barr virus (EBV) with Sjogren's syndrome: differential EBV expression between epithelial cells and lymphocytes

45 Fingeroth JD, Weis JJ, Tedder TF, et al. Epstein-Barr virus receptor of human B lymphocytes is the C3d receptor CR2. Proc Natl Acad Sci U S A 1984;81:4510-14.

$46 \mathrm{Li}$ QX, Young LS, Niedobitek G, et al. Epstein-Barr virus infection and replication in a human epithelial cell system. Nature 1992;356:347-50.

47 Shapiro IM, Volsky DJ. Infection of normal human epithelial cells by Epstein-Barr virus. Science 1982;219: 1225-9.

48 Yoshiyama H, Imai S, Shimizu N, et al. Epstein-Barr virus infection of human gastric carcinoma cells: implication of the existence of a new virus receptor different from CD21. f Virol 1997;71:5688-91

49 Imai S, Nishikawa J, Takada K. Cell-to-cell contact as an efficient mode of Epstein-Barr virus infection of diverse human epithelial cells. F Virol 1998;72:4371-8.

50 Yoshiyama H, Shimizu N, Takada K. Persistent EpsteinBarr virus infection in a human T-cell line: unique program Barr virus infection in a human T-cell line: unique prog
of latent virus expression. $E M B O f 1995 ; 14: 3706-11$.

51 Shimizu N, Yoshiyama H, Takada K. Clonal propagation of Epstein-Barr virus (EBV) recombinants in EBV-negative Akata cells. F Virol 1996;70:7260-3.

52 Sixbey JW, Yao Q. Immunoglobulin A-induced shift of Epstein-Barr virus tissue tropism. Science 1992;255:157880

53 Fingeroth JD, Diamond ME, Sage DR, et al. CD21dependent infection of an epithelial cell line, 293, by Epstein-Barr virus. F Virol 1999;73:2115-25.

54 Iwasaki Y, Chong J, Hayashi Y, et al. Establishment and characterization of a human Epstein-Barr virus-associated gastric carcinoma in SCID mice. F Virol 1998;72:8321-6.

55 Tajima M, Komura M, Okinaga $K$ Establishment of Epstein-Barr virus-positive human gastric epithelial cell lines. 尹pn $\mathcal{f}$ Cancer Res 1998;89:262-8.

56 Takasaka N, Tajima M, Okinaga K, et al. Productive infection of Epstein-Barr virus (EBV) in EBV-genomepositive epithelial cell lines (GT38 and GT39) derived from gastric tissues. Virology 1998;247:152-9.

57 Takimoto $\mathrm{T}$, Ogura $\mathrm{H}$, Sato $\mathrm{H}$, et al. Isolation of transforming and early antigen-inducing Epstein-Barr virus from nasopharyngeal carcinoma hybrid cells (NPC-KT). f Natl Cancer Inst 1985;74:57-60.

58 Zhang HY, Yao K, Zhu H, et al. Expression of the EpsteinBarr virus genome in a nasopharyngeal carcinoma epithelial tumor cell line. Int $\mathcal{F}$ Cancer 1990;46:944-9.

59 Knox PG, Li Q, Rickinson $\mathrm{AB}$, et al. In vitro production of stable Epstein-Barr virus-positive epithelial cell clones which resemble the virus:cell interaction observed in nasopharyngeal carcinoma. Virology 1996;215:40-50.

60 Kieff E. Epstein-Barr virus and its replication. In: Fields BN, Knipe DM, Howley PM, eds. Virology, 3rd ed. Philadelphia: Lippincott-Raven, 1996:2343-96.

61 Shimizu N, Tanabe-Tochikura A, Kuroiwa Y, et al. Isolation of Epstein-Barr virus (EBV)-negative cell clones from the EBV-positive Burkitt's lymphoma (BL) line Akata: malignant phenotypes of BL cells are dependent on EBV. $\mathcal{F}$ Virol 1994;68:6069-73.

62 Komano J, Sugiura M, Takada K. Epstein-Barr virus contributes to the malignant phenotype and to apoptosis resistance in Burkitt's lymphoma cell line Akata. F Virol 1998;72:9150-6.

63 Chodosh J, Holder VP, Gan Y, et al. Eradication of latent Epstein-Barr virus by hydroxyurea alters the growthtransformed cell phenotype. F Infect $D$ is 1

64 Ruf IK, Rhyne PW, Yang $\mathrm{H}$, et al. Epstein-Barr virus regulates c-MYC, apoptosis, and tumorigenicity in Burkitt lymphoma. Mol Cell Biol 1999;19:1651-60.

65 Nishikawa J, Imai S, Oda T, et al. Epstein-Barr virus promotes epithelial cell growth in the absence of EBNA2 and LMP1 expression. F Virol 1999;73:1286-92.

66 Wei MX, Ooka T. A transforming function of the BARF1 gene encoded

67 Zur Hausen A, Brink AATP, Craanen ME, et al. Unique transcription pattern of Epstein-Barr virus (EBV) in EBVcarrying gastric adenocarcinomas: expression of the trans-
forming BARF1 gene. Cancer Res 2000;60:2745-8. 